\title{
Molecular characterization of multidrug-resistant Mycobacterium tuberculosis isolated from South-central in China
}

\author{
Xiao-li Yu ${ }^{1,2}$, Zi-lu Wen ${ }^{1,2}$, Gao-zhan Chen ${ }^{1}$, Rui Li ${ }^{1}$, Bing-bing Ding ${ }^{1}$, Yu-feng Yao ${ }^{2}$, Yao $\mathrm{Li}^{3}$, Hai Wu ${ }^{3}$, \\ Xiao-kui Guo ${ }^{2}$, Hong-hai Wang ${ }^{3}$ and Shu-lin Zhang ${ }^{2}$
}

Rifampicin (RIF) and isoniazid (INH) Mycobacterium tuberculosis isolates were characterized from South-central China and transmission patterns within the Beijing genotype were detected in multidrug-resistant isolates. Six genetic regions, including rpoB for RIF, and katG, inhA, ahpC, mabA-inhA promoter and oxyR-ahpC intergenic region for INH were analyzed by DNA sequencing in 60 multidrug-resistant isolates, including 7 extensively drug-resistant isolates. The genomic deletion RD105 was characterized by genotyping. The results showed that $91.7 \%$ of MDR isolates carried mutations in the rpoB gene and $85.0 \%$ of the MDR isolates had at least one mutation in the INH resistance-associated loci detected. In total, these six genetic regions are responsible for $95.0 \%$ of MDR isolates. Mutations in the XDR isolates were focused on rpoB 531 or rpoB 526, and katG 315 , correlating to a higher frequency level of resistance to RIF MIC $\geqslant 8 \mu \mathrm{g} \mathrm{ml}^{-1}$ and INH MIC $\geqslant 4 \mu \mathrm{g} \mathrm{m}^{-1}$. Three novel katG mutants (G273S, I266T and P232S) and three new alleles (E458A, S509R and P535S) in the rpoB gene were identified. Among the 85 clinical isolates, 78 are Beijing genotypes and the other 7 are non-Beijing genotypes. The results present the identification of genetic markers in $M$. tuberculosis isolates, some of which may be unique to this particular geographic niche. An understanding of the mutations in these drug-resistant strains may aid in choosing the appropriate chemotherapy regimens on the pharmacogenetic properties of the mutations for the prevention and control of tuberculosis.

The Journal of Antibiotics (2014) 67, 291-297; doi:10.1038/ja.2013.133; published online 11 December 2013

Keywords: Beijing genotypes; extensively drug resistance; M. tuberculosis; multidrug-resistance; mutation

\section{INTRODUCTION}

Tuberculosis (TB) remains one of the major causes of death around the world, especially due to the emergence of multidrug-resistant TB (MDR-TB) and extensively drug-resistant TB (XDR-TB). There were approximately 440000 cases of MDR-TB in 2008, which were resistant to both rifampicin (RIF) and isoniazid (INH). Almost $50.0 \%$ of MDR-TB cases worldwide are estimated to occur in China and India. ${ }^{1}$ Approximately $8.0 \%$ of the patients with MDR-TB have XDR-TB, which is defined as resistance to at least RIF and INH, plus resistance to any fluoroquinolone and at least one of three injectable anti-TB drugs (capreomycin, kanamycin or amikacin). ${ }^{2}$ Therefore, controlling tuberculosis caused by drug-resistant $M$. tuberculosis has become an urgent public health problem in many regions of the world, particularly in developing countries.

RIF and INH are the principal first-line drugs used in combination in tuberculosis chemotherapy. Therefore, it is important to understand the molecular basis for this resistance. ${ }^{3}$ RIF, as a broad spectrum derivative of RIF, exerts its anti-tuberculosis role by binding to the bacterial RNA polymerase, thereby inhibiting RNA synthesis.
Ninety-five percent of the resistance to RIF in M. tuberculosis is due to single mutation in an 81-bp core region, termed the RIF resistancedetermining region (RRDR) of the $r p o B$ gene, which encodes the beta subunit of DNA-dependent RNA polymerase. ${ }^{4} \mathrm{INH}$ is the first-line drug responsible for the initial dramatic decrease in actively metabolizing bacilli during treatment of $\mathrm{TB}$, yet its mechanism of resistance remains only partially understood. Unlike RIF, INH resistance is associated with mutations in multiple loci, such as the catalase-peroxidase gene $(k a t G)$, the enoyl-ACP reductase gene $(\operatorname{inh} A)$ and its promoter, the alkyl hydroperoxide reductase gene $(a h p C)$, and the intergenic region between the $\operatorname{oxyR}$ and $a h p C$ genes. ${ }^{5,6}$

Traditional culture-based methods of testing for drug resistance can take at least 4 weeks, as M. tuberculosis is a slow-growing organism, leading to higher mortality and the further spread of MDR infections. Thus, various molecular methods have been used to detect MDR-TB by identifying mutations associated with drug resistance. ${ }^{7,8}$ Among these methods, DNA sequencing is the most direct and reliable, and can rapidly detect both known and novel mutations.

${ }^{1}$ School of Biology and Pharmaceutical Engineering, Wuhan Polytechnic University, Wuhan, China; ${ }^{2}$ Department of Medical Microbiology and Parasitology, Shanghai Jiao Tong University School of Medicine, Shanghai, China and ${ }^{3}$ State Key Laboratory of Genetic Engineering, Institute of Genetics, Fudan University, Shanghai, China 
It has been reported that some mutations have a geographical distribution..$^{8-10}$ However, little data have been available on the molecular characterization of multidrug-resistant clinical isolates of M. tuberculosis from South-central region in China. In this study, the type and frequency of mutations in the rpoB, katG, mabA-inhA regulatory region, the structural gene, $\operatorname{ahpC}$, and the $\operatorname{axy} R-a h p C$ intervening region were investigated. The MICs of RIF and INH for MDR strains were determined. These studies identified genetic markers of MDR M. tuberculosis isolates that are unique to this geographical region and will further the understanding of the molecular mechanism of drug resistance, particularly multi-drug resistance in $M$. tuberculosis. Currently, the mechanism of multidrug resistance in $M$. tuberculosis still needs to be elucided. Based on the analysis of the relationship between the gene typing and MIC, the findings of present study further reveal the molecular mechanism of MDR-TB strains in China. Also, the results help to supplement and optimize the current molecular detection techniques, which assist in the personalized treatment for the MDR-TB patients. In addition, the molecular characterization identified recent transmission patterns of multidrug-resistant isolates of the Beijing genotype in South-central China.

Large numbers of reports have confirmed that the Beijing genotype strains had a deletion in RD105, which was a unique characteristics of Beijing genotypes isolates. Therefore, the deletion of RD105 sequence can serve as a simple and rapid method to identify Beijing genotypes strains. Analyzing the distribution and transmission of MTB in this area can provide a theoretical basis for controlling and preventing infectious diseases in Hubei Province. ${ }^{11-12}$

\section{MATERIALS AND METHODS}

\section{Clinical isolates and drug susceptibility testing (DST)}

A total of 1733 clinical isolates of M. tuberculosis was obtained from 5299 patients with pulmonary tuberculosis in the Wuhan Medical Treatment Center, Hubei, South-central China, from August 2009 to July 2010. All isolates were routinely cultured with egg-based Löwenstein-Jensen medium at $37^{\circ} \mathrm{C}$ and were evaluated by proportion method for DST. ${ }^{13}$

Proportion method was performed on DSTs use the following drug concentrations in the modified Löwenstein-Jensen medium: RIF, $40.0 \mu \mathrm{g} \mathrm{ml}^{-1}$, INH, $0.2 \mu \mathrm{g} \mathrm{ml}^{-1}$; ethambutol, $2.0 \mu \mathrm{g} \mathrm{ml}^{-1}$; streptomycin, $4 \mu \mathrm{g} \mathrm{ml}^{-1}$. In addition, some second-line drugs, widely used in China, were also performed on DSTs with the following concentrations: kanamycin, $30.0 \mu \mathrm{g} \mathrm{ml}^{-1}$; paramycin, $1.0 \mu \mathrm{g} \mathrm{ml}^{-1}$; protionamide (Pto), $40.0 \mu \mathrm{g} \mathrm{ml}^{-1}$; ofloxacin, $2.0 \mu \mathrm{g} \mathrm{ml}^{-1}$; thiophen-2-carboxylic acid hydrazine (TCH), $5.0 \mu \mathrm{g} \mathrm{ml}^{-1}$; para-nitrobenzoic acid (PNB), $500 \mu \mathrm{g} \mathrm{ml}^{-1}$

The sodium 2,3-bi(2-methoxy-4-nitro-5-sulfophenyl)-2H-tetrazolium-5carboxanilide inner salt (XTT) colorimetric method ${ }^{14}$ was performed in 7H9$\mathrm{S}$ medium containing Middlebrook $7 \mathrm{H} 9$ broth, $10 \%$ oleic acid albumin dextrose catalase and $0.5 \%$ glycero and $0.1 \%$ Casitone. By using 96 -well plates, the MIC was determined with 7H9-S medium containing twofold dilution series of the RIF ranging from 0.125 to $8 \mu \mathrm{g} \mathrm{ml}^{-1}$, the INH ranging from 0.063 to $4 \mu \mathrm{g} \mathrm{ml}^{-1}$.

Sixty-five clinically resistant isolates, including $60 \mathrm{MDR}$ strains and 7 extensively drug resistant (XDR) strains, were selected from 664 (38.3\%, 664/ 1733) drug-resistant strains, and 20 pan-susceptible stains were also randomly chosen as control (Table 1).

\section{DNA extraction and isolates identified}

Genomic DNA of M. tuberculosis isolates was extracted as previously described. ${ }^{15}$ M. tuberculosis culture isolates previously identified by conventional biochemical methods were confirmed by $16 \mathrm{~S}$ rRNA gene sequencing. ${ }^{16}$

PCR amplification and sequencing

Oligonucleotide primers were designed from the M. tuberculosis $\mathrm{H} 37 \mathrm{Rv}$ genome sequence ${ }^{17}$ using Primer Premier 5.0 (PREMIER Biosoft, Palo Alto,
Table 1 Prevalence of drug-resistance phenotypes among clinical $M$. tuberculosis isolates $(n=85)$

\begin{tabular}{lccc}
\hline & & \multicolumn{2}{c}{ No. of isolates } \\
\cline { 3 - 4 } Resistance phenotypes & No. of isolates & Beijing $(\mathrm{n}=78)$ & Non-Beijing $(\mathrm{n}=7)$ \\
\hline Fully susceptible & 20 & 18 & 2 \\
MDR & 60 & 56 & 4 \\
XDR & 8 & & \\
Other phenotypes & 5 & & \\
S & 1 & 1 & 1 \\
H & 1 & 1 & \\
HS & 2 & 2 & \\
HLP & 1 & &
\end{tabular}

Abbreviations: $\mathrm{H}$, isonicotinic acid hydrazide; L, levofloxacin; MDR, multidrug resistance; $\mathrm{P}$, pyrazinamide; $\mathrm{S}$, streptomycin; XDR, extensively drug resistance.

Table 2 Primers used in this study and resulting PCR products

\begin{tabular}{|c|c|c|c|c|}
\hline Drug & $\begin{array}{l}\text { Accession no. } \\
\text { (Genbank) }\end{array}$ & Primer & Sequence $\left(5^{\prime} \rightarrow 3^{\prime}\right)$ & $\begin{array}{c}\text { Product } \\
\text { (bp) }\end{array}$ \\
\hline \multirow[t]{2}{*}{ Rifampicin } & L27989 & $r p o B-F$ & CGCTTGCACGAGGGTCAGA & 428 \\
\hline & & $r p o B-R$ & GTTTCGATCGGGCACATCC & \\
\hline \multirow[t]{10}{*}{ Isoniazid } & X68081 & katG-F & TCGGCGATGAGCGTTACAG & 459 \\
\hline & & katG-R & CGTCCTTGGCGGTGTATTG & \\
\hline & BX842579 & $a h p C-F$ & ACCTTTGCCTGACAGCGACT & 667 \\
\hline & & $a h p C-R$ & TAGGCCGAAGCCTTGAGGAG & \\
\hline & СР003248 & $\operatorname{inh} A-F$ & CGGCATGGGTATGGGCCACT & 751 \\
\hline & & $\operatorname{inh} A-R$ & CGGCGTCGCATCCTTCATGT & \\
\hline & Z81451 & $\begin{array}{l}\text { oxyR- } \\
\text { ahpC-F }\end{array}$ & CGCAACGTCGACTGGCTCATA & 359 \\
\hline & & $\begin{array}{l}\text { oxyR- } \\
\text { ahpC-R }\end{array}$ & GCCTGGGTGTTCGTCACTGGT & \\
\hline & U41388 & $\begin{array}{l}m a b A- \\
i n h A-F\end{array}$ & CCTCGCTGCCCAGAAAGGGA & 248 \\
\hline & & $\begin{array}{l}\text { mabA- } \\
\operatorname{inh} A-R\end{array}$ & ATCCCCCGGTTTCCTCCGGT & \\
\hline
\end{tabular}

CA, USA) and Oligo 6 software (Molecular Biology Insights, Inc., Cascade, $\mathrm{CO}$, USA). The uniqueness of the sequences of the primers designed was analyzed with the Blast search (http://www.ncbi.nlm.nih.gov). The nucleotide sequences for the mutant genes obtained in the present study were deposited in the GenBank database (Table 2). Primers were synthesized by Invitrogen Bio Co. (Shanghai, China). Six fragments were amplified and sequenced: $r p o B$ (including the 81-bp RRDR), kat G (including codon 315), inh A, ahpC gene, mabA-inhA regulatory region and the $\operatorname{oxyR}$-ahpC intergenic region. Sequence data were assembled and analyzed by CLUSTAL W software (European Bioinformatics Institute). PCR amplification was performed with the EDC-810 model thermal cycler (Eastwin Life Sciences, Inc., Beijing, China), and the Pfu Taq DNA polymerase with high fidelity was used to avoid false priming. The amplicons were purified with the E.Z.N.A. MicroElute Cycle-Pure Kit (Omega, Lilburn, GA, USA). Sequence analysis was determined on both strands by direct sequencing of the PCR products on an automated model 377 DNA sequencer (Applied Biosystems, Foster City, CA, USA) with fluorescence-labeled dideoxynucleotide terminators (ABI Prism Big Dye terminator cycle sequencing ready reaction kit; Sangaon Biotech Co., Ltd, Shanghai, China). 


\section{Genotyping method}

The identification of Beijing genotypes strains was performed using the RD105 deletion-targeted amplified by PCR. ${ }^{18}$ Primers were designed flanking this 3467 base pair (bp) deletion polymorphism P1 and P2 to detect the presence or absence of this deletion in the M. tuberculosis genome. A third primer P3, which is internal to deletion RD105, was also utilized. A $\chi^{2}$ test was performed with SPSS17.0 software (SPSS China, Shanghai, China) to analyze the distribution characteristics of Beijing genotypes.

\section{RESULTS}

All 85 strains chosen for analysis were confirmed as M. tuberculosis by $16 \mathrm{~S}$ rRNA gene sequencing. Specific resistant genes or regulatory regions were sequenced, and the sequencing results were compared with the DST results. No mutation was found in the pan-susceptible isolates.

\section{Mutation patterns in MDR and XDR isolates}

Forty-nine of the sixty MDR were found to have a mutation in the six characterized genetic regions. Forty-one MDR isolates $(68.3 \%, 41 / 60)$ were found to carry mutations in the rpoB gene and $k a t G$ gene, and 21 isolates $(35.0 \%, 21 / 60)$ contained mutations in both rpoB531 and katG315. Sequencing of three MDR isolates failed to identify any mutations in the six regions investigated. Therefore, these six genetic regions account for 95.0\% (57/60) of the MDR isolates characterized.

Of the 49 MDR isolates, 44 (89.8\%) were Beijing genotypes and the other 5 were non-Beijing genotypes. Among the 36 non-MDR, $34(94.4 \%)$ were Beijing genotypes and 2 isolates were non-Beijing genotypes $\left(\chi^{2}=0.593, P=0.441\right)$.

Among the seven XDR isolates, four were found to possess alterations in rpoB 531 and $k a t G 315$, and one of them had a third mutation in the mabA-inhA regulatory region (C-15T; Table 3). Two of the remaining three XDR isolates carried mutations in three fragments, one had mutations in $r p o B$ H526L (CAC $\rightarrow$ CTC), kat $G$ S315T $($ AGC $\rightarrow$ ACC) and inhA A190S $($ GCC $\rightarrow$ TCC); and the other isolate had a mutation in $r p o B$ S531L (TCG $\rightarrow$ TTG) with a seven amino acids (GKTHGAG) insertion mutation in katG 279-280, plus base substitutions $\mathrm{C}-15 \mathrm{~T}$ in mabA-inhA regulatory region. The last isolate harbored mutations in both $r p o B$ Q517(CAG deletion) and $m a b A$-inhA regulatory region $\mathrm{C}-15 \mathrm{~T}$. All of the seven XDR were nonBeijing genotypes.

\section{RIF resistances and $r p o B$ gene}

Of the 60 RIF resistance isolates, $55(91.7 \%, 55 / 60)$ carried mutations in RRDR of the $r p o B$ gene, 45 isolates had a single-point mutation, 8 had double mutations $(13.3 \%, 8 / 60), 2$ had a deletion that was the same in both isolates and 5 have no mutation $(8.3 \%, 5 / 60$, MIC $>$ $2-8 \mu \mathrm{g} \mathrm{ml}^{-1}$; Table 4$)$. The most frequently mutated $r p o B$ codons were codon 531, 526 and 516, with mutation frequencies of $51.7 \%$ $\left(31 / 60, \mathrm{MIC} \geqslant 2-8 \mu \mathrm{g} \mathrm{ml}^{-1}\right), 18.3 \%\left(11 / 60, \mathrm{MIC}>2-8 \mu \mathrm{g} \mathrm{ml}^{-1}\right)$ and $10.0 \%\left(6 / 60, \mathrm{MIC}>2-8 \mu \mathrm{g} \mathrm{ml}^{-1}\right)$, respectively. Consistent with previous reports, the mutation S531L was the most common mutation in $r p o B$ gene. Codon 526 harbored the most variable mutations. Six isolates exhibited codon 516 mutations, including D516V and D516G. Eight isolates with seven different types of double mutations were identified. In addition, one deletion was detected at codon 517 (CGC, $\mathrm{MIC} \geqslant 4 \mu \mathrm{g} \mathrm{ml}^{-1}$ ) in two stains. Of these mutations, three have not previously been described, E458A (GCG $\rightarrow$ GAG; GenBank: JF812083), S509R (AGC $\rightarrow$ AGA) and P535S (CCC $\rightarrow$ TCC). Five isolates $(8.3 \%)$ had no mutation in the RRDR of $r p o B$ gene. There are 55 high-level $\left(\mathrm{MIC} \geqslant 4-8 \mu \mathrm{g} \mathrm{ml}^{-1}\right)$ and 5 low-level $(\mathrm{MIC} \leqslant 0.5-$ $4 \mu \mathrm{g} \mathrm{ml}^{-1}$ ) RIF resistance strains among 60 MDRs.

Of the 55 RIF mutant strains, 51 (92.7\%) were Beijing genotypes and $4(7.3 \%)$ were non-Beijing genotypes. Besides, among the 30 RIFsusceptible strains, 27 (90.0\%) were Beijing genotypes and $3(10.0 \%)$ isolates were non-Beijing genotypes $\left(\chi^{2}=0.191, P=0.662\right)$.

INH resistances and $k a t G, i n h A, \operatorname{ahpC} m a b A$-inhA and oxyR-ahpC In $84.4 \%(54 / 64)$ of the INH resistances strains, at least one mutation was found in the $k a t G$, inhA, ahpC, mabA-inhA regulatory region and oxyR-ahpC intergenic region, which included mutations at kat $G$ codon 315 in isolates. And no mutation was found in $10 \mathrm{MDR}$ isolates (15.6\%, MIC $\geqslant 2-4 \mu \mathrm{g} \mathrm{ml}^{-1}$; Table 5). Of the $64 \mathrm{INH}$ resistances, $70.3 \%(45 / 64)$ had genetic alterations in $k a t G$ nucleotide fragment. Mutations at codon 315 in the kat $G$ region contributed the majority of INH resistance, with high frequency of $62.5 \%(40 / 64$, MIC $>1-4 \mu \mathrm{g} \mathrm{ml}^{-1}$ ) isolates, and the common base substitution mutation S315T (AGC $\rightarrow$ ACC) was the most frequently alteration. Three isolates carried other exchanges in codon 315. In addition, we found three novel types of mutation in katG gene, G273S (GGT $\rightarrow$ AGT, MIC $>4 \mu \mathrm{g} \mathrm{ml}^{-1}$; GenBank: HQ913569), I266T (ATC $\rightarrow$ ACC, $\mathrm{MIC}=4 \mu \mathrm{g} \mathrm{ml}^{-1}$; GenBank: HQ913567) and P232S (CCG $\rightarrow$ TCG,

Table 3 Mutations in genes associated with INH and RIF of the XDR-TB clinical isolates $(n=7)$

\begin{tabular}{|c|c|c|c|c|c|c|c|}
\hline \multirow[b]{2}{*}{ Isolates } & \multirow[b]{2}{*}{ Drug resistance } & \multicolumn{6}{|c|}{ Genetic alteration } \\
\hline & & $r p o B$ & katG & $a h p C$ & $\operatorname{inh} A$ & oxyR-ahpC & mabA-inhA \\
\hline \multirow[t]{2}{*}{ WH4O } & IRSKL & S531L & S315T & WT & WT & WT & WT \\
\hline & & $\mathrm{TCG} \rightarrow \mathrm{TTG}$ & $\mathrm{AGC} \rightarrow \mathrm{ACC}$ & & & & \\
\hline \multirow[t]{2}{*}{ WH50 } & IRSELK & S531L & S315T & WT & WT & WT & WT \\
\hline & & $\mathrm{TCG} \rightarrow \mathrm{TTG}$ & $\mathrm{AGC} \rightarrow \mathrm{ACA}$ & & & & \\
\hline \multirow[t]{2}{*}{ WH72 } & IRSELK & S531L & S315T & WT & WT & WT & C-15T \\
\hline & & $\mathrm{TCG} \rightarrow \mathrm{TTG}$ & $\mathrm{AGC} \rightarrow \mathrm{ACC}$ & & & & \\
\hline \multirow[t]{2}{*}{ WH88 } & IRSELPK & H526L & S315T & WT & A190S GCC $\rightarrow$ TCC & WT & WT \\
\hline & & $\mathrm{CAC} \rightarrow \mathrm{CTC}$ & $\mathrm{AGC} \rightarrow \mathrm{ACC}$ & & & & \\
\hline \multirow[t]{2}{*}{ WH9O } & IRSEPLK & S531L & GKTHGAG insert in & WT & WT & WT & C-15T \\
\hline & & $\mathrm{TCG} \rightarrow \mathrm{TTG}$ & $279-280$ & & & & \\
\hline WH93 & IRSELK & Q517(CAG deletion) & WT & WT & WT & WT & C-15T \\
\hline \multirow[t]{2}{*}{ WH100 } & IRSELK & S531L & S315T & WT & WT & WT & WT \\
\hline & & $\mathrm{TCG} \rightarrow \mathrm{TTG}$ & $\mathrm{AGC} \rightarrow \mathrm{ACC}$ & & & & \\
\hline
\end{tabular}

Abbreviations: E, ethambutol; I, isoniazid (INH); K, kanamycin; L, levofloxacin; P, p-aminosalicylic acid; R, rifampin (RIF); S, streptomycin; WT, wild type; XDR-TB, extensively drug-resistant 
Table 4 Distrbution of mutations in the $r p o B$ gene among MDR-TB clinical isolates $(n=60)$

\begin{tabular}{|c|c|c|c|c|c|c|}
\hline \multirow[b]{2}{*}{ Locus } & \multirow[b]{2}{*}{ Mutations $^{\mathrm{a}}$} & \multirow[b]{2}{*}{ Nucleotide change } & \multirow[b]{2}{*}{ No. of isolates (\%) } & \multicolumn{2}{|c|}{ No. of isolates } & \multirow[b]{2}{*}{$M I C\left(\mu g m I^{-1}\right.$, } \\
\hline & & & & Beijing $(n=56)$ & non-Beijing $(n=4)$ & \\
\hline \multirow{2}{*}{531} & & & & 1 & & 4 \\
\hline & & & & 1 & & 2 \\
\hline \multirow[t]{4}{*}{526} & H526Y & $\mathrm{CAC} \rightarrow \mathrm{TAC}$ & $2(3.3)$ & 2 & & $>8$ \\
\hline & $\mathrm{H} 526 \mathrm{R}$ & $\mathrm{CAC} \rightarrow \mathrm{CGC}$ & $1(1.7)$ & 1 & & None $^{\mathrm{b}}$ \\
\hline & H526P & $\mathrm{CAC} \rightarrow \mathrm{CCC}$ & $1(1.7)$ & 1 & & $>8$ \\
\hline & H526C & $\mathrm{CAC} \rightarrow \mathrm{TGC}$ & $1(1.7)$ & 1 & & 2 \\
\hline \multirow[t]{2}{*}{526 and 535} & H526T & $\mathrm{CAC} \rightarrow \mathrm{ACC}$ & $1(1.7)$ & 1 & & $>8$ \\
\hline & P535S & $\mathrm{CCC} \rightarrow \mathrm{TCC}$ & & & & \\
\hline 526 and 509 & H526R & $\mathrm{CAC} \rightarrow \mathrm{CGC}$ & $1(1.7)$ & 1 & & $\geqslant 4$ \\
\hline \multirow[t]{4}{*}{516 and 511} & D516G & $\mathrm{GAC} \rightarrow \mathrm{GGC}$ & $2(3.3)$ & 1 & 1 & $\geqslant 8$ \\
\hline & H511P & $\mathrm{CTG} \rightarrow \mathrm{CCG}$ & & & & \\
\hline & D516V & $\mathrm{GAC} \rightarrow \mathrm{GTC}$ & $1(1.7)$ & 1 & & \\
\hline & H511P & $\mathrm{CTG} \rightarrow \mathrm{CCG}$ & & & & \\
\hline \multirow[t]{2}{*}{533} & L533P & $\mathrm{CTG} \rightarrow \mathrm{CCG}$ & $1(1.7)$ & 1 & & 0.5 \\
\hline & L533L & $\mathrm{CTG} \rightarrow \mathrm{TTG}$ & $1(1.7)$ & 1 & & 4 \\
\hline \multirow{2}{*}{533 and 511} & L533P & $\mathrm{CTG} \rightarrow \mathrm{CCG}$ & $1(1.7)$ & 1 & & 4 \\
\hline & H511P & $\mathrm{CTG} \rightarrow \mathrm{CCG}$ & & & & \\
\hline \multirow[t]{2}{*}{513 and 458} & Q513P & $\mathrm{CAA} \rightarrow \mathrm{CCA}$ & $1(1.7)$ & 1 & & $>8$ \\
\hline & E458A & $\mathrm{GAG} \rightarrow \mathrm{GCG}$ & & & & \\
\hline 517 & Q517del ${ }^{b}$ & $\mathrm{CAG} \rightarrow \mathrm{del}$ & $2(3.3)$ & 2 & & $\geqslant 4$ \\
\hline
\end{tabular}

Abbreviations: del, deletion; MDR-TB, multidrug-resistant tuberculosis.

a Mutations in the $r p o B$ gene are denoted as follows: first, the amino-acid residue in the wild-type sequence; second, the codon position and third, the amino-acid residue in the mutated sequence. bacterial strain has died.

$\mathrm{MIC}=4 \mu \mathrm{g} \mathrm{ml}^{-1}$; GenBank: HQ913568). Interestingly, a 10.8-kb fragment deletion in WH56 isolate comprising the kat $G$ with seven upstream genes and one downstream gene was found in one MDR isolate (Figure 1). In addition, one novel insert mutation was identified in the $k a t G$ gene, resulting in a seven-amino-acid, GKTHGAG, insert between codons 279 and $280\left(\mathrm{MIC} \geqslant 4 \mu \mathrm{g} \mathrm{ml}^{-1}\right)$.

Mutations in inhA and $a h p C$ with their noncoding regions were identified in $21.9 \%(14 / 64)$ isolates. No alteration was found in the inhA structural gene, whereas one mutation was detected in $a h p C$ structural gene: A190S (GCC $\rightarrow$ TCC). In contrast, $12.5 \%$ $(8 / 64)$ of the INH-resistant isolates harbored base substitutions $\mathrm{C}-15 \mathrm{~T}$ in the mabA-inhA regulatory region. Three of them had an additional mutation in the katG gene. 9.4\% (6/64) isolates had nucleotide substitutions at loci of $-46,-52$ and -54 in the oxyR-ahpC intergenic region, and two of isolates had an additional mutation in $k a t G$ gene. There are 56 high-level $\left(\mathrm{MIC} \geqslant 2-4 \mu \mathrm{g} \mathrm{ml}^{-1}\right.$ ) and 8 lowlevel (MIC $\left.\leqslant 0.25-2 \mu \mathrm{g} \mathrm{ml}^{-1}\right) \quad$ INH resistance strains among 64 MDRs.

Of the 64 INH mutant strains, 59 (92.2\%) were Beijing genotypes and $5(7.8 \%)$ were non-Beijing genotypes. Among the $30 \mathrm{INH}-$ susceptible strains, $19(90.5 \%)$ were Beijing genotypes and $2(9.5 \%)$ isolates were non-Beijing genotypes $\left(\chi^{2}=0.061, P=0.804\right)$.

\section{Genotyping of the Beijing genotypes strains}

PCR was performed on the 85 clinical isolates of $M$. tuberculosis to identify the Beijing genotype. We obtained a 1466-bp PCR amplified product for the non-Beijing and $\mathrm{H} 37 \mathrm{Rv}$, and a 761-bp for the Beijing genotype (Figure 2). PCR on 78 (91.8\%) obtained a 761-bp product, identifying a Beijing isolate and 7 strains $(8.2 \%)$ did not generate the expected PCR products, identifying a non-Beijing isolate. The H37Rv strain was identified as a non-Beijing isolate (Table 1).

\section{DISCUSSION}

It has been reported that the frequency of $r p o B$ mutations range from $76.0 \%(19 / 25)^{19}$ to $99.0 \%(102 / 103),{ }^{20}$ suggesting that mutations in the $r p o B$ gene are possible molecular markers for MDR-TB. In this study, the mutation frequency of $r p o B$ gene was $91.7 \%(55 / 60)$ consistent with the observed resistance prevalence around the world..$^{8,21-23}$ The most frequently mutated $r p o B$ codons were 531, 526 and $516\left(\mathrm{MIC} \geqslant 2-8 \mu \mathrm{g} \mathrm{ml}^{-1}\right)$, which have been reported elsewhere, ${ }^{10,20,21}$ indicating that there is no geographic difference in the main mutation types and mutation rates of $r p o B$ gene in Southcentral China. Double mutations were observed in $8 / 60$ (13.3\%) isolates in this study, which is higher than reported in other studies from Shanghai, $7.4 \%(18 / 242),{ }^{23}$ and Germany, $2.0 \%,{ }^{20}$ but lower 
Table 5 Mutations in the genes of katG, inhA, ahpC mabA-inhA and oxyR-ahpC INH-resistant isolates $(n=64)$

\begin{tabular}{|c|c|c|c|c|c|c|c|}
\hline \multirow[b]{2}{*}{ Genes } & \multicolumn{3}{|c|}{ Mutations $s^{\mathrm{a}, \mathrm{b}}$} & \multirow[b]{2}{*}{ No. of isolates (\%) } & \multicolumn{2}{|c|}{ No. of isolates } & \multirow[b]{2}{*}{$M I C\left(\mu g m l^{-1}\right)$} \\
\hline & Locus & Nucleotides & Amino acids & & Beijing $(n=59)$ & non-Beijing $(n=59)$ & \\
\hline \multirow[t]{9}{*}{ katG } & katG 315 & $\mathrm{AGC} \rightarrow \mathrm{ACC}$ & $\mathrm{S} \rightarrow \mathrm{T}$ & $33(51.6)$ & 26 & 2 & $\geqslant 4$ \\
\hline & & & & & 4 & 1 & $\leqslant 1-2$ \\
\hline & & $\mathrm{AGC} \rightarrow \mathrm{AAC}$ & $\mathrm{S} \rightarrow \mathrm{N}$ & $1(1.6)$ & 1 & & $\geqslant 4$ \\
\hline & & $\mathrm{AGC} \rightarrow \mathrm{ACA}$ & $\mathrm{S} \rightarrow \mathrm{T}$ & $1(1.6)$ & 1 & & 4 \\
\hline & & $\mathrm{AGC} \rightarrow \mathrm{GGC}$ & $\mathrm{S} \rightarrow \mathrm{G}$ & $1(1.6)$ & 1 & & $\geqslant 4$ \\
\hline & katG 232 & $\mathrm{CCG} \rightarrow \mathrm{TCG}$ & $\mathrm{P} \rightarrow \mathrm{S}$ & $1(1.6)$ & 1 & & 4 \\
\hline & katG 266 & $\mathrm{ATC} \rightarrow \mathrm{ACC}$ & $\mathrm{I} \rightarrow \mathrm{T}$ & $1(1.6)$ & 1 & & 4 \\
\hline & katG $279-280$ & 7 Amino acids & & $1(1.6)$ & 1 & & $\geqslant 4$ \\
\hline & & GKTHGAG insertion & & & & & \\
\hline \multirow[t]{4}{*}{ kat $G$ and $\operatorname{oxy} R$-ahpC } & katG & 10.8 kb Deletion & & $1(1.6)$ & 1 & & None $^{\mathrm{c}}$ \\
\hline & oxyR-ahpC -52 & $C \rightarrow T$ & & & & & \\
\hline & katG 273 & $\mathrm{GGT} \rightarrow \mathrm{AGT}$ & $G \rightarrow S$ & $1(1.6)$ & 1 & & $>4$ \\
\hline & oxyR-ahpC -52 & $C \rightarrow T$ & & & & & \\
\hline \multirow[t]{3}{*}{ katG and mabA-inhA } & katG 315 & $\mathrm{AGC} \rightarrow \mathrm{ACC}$ & $\mathrm{S} \rightarrow \mathrm{T}$ & $3(4.7)$ & 3 & & \\
\hline & & & & & & & 4 \\
\hline & mabA-inhA -15 & $\mathrm{C} \rightarrow \mathrm{T}$ & & & & & \\
\hline \multirow[t]{2}{*}{ kat $G$ and inhA } & katG 315 & $\mathrm{AGC} \rightarrow \mathrm{ACC}$ & $S \rightarrow T$ & $1(1.6)$ & 1 & & 4 \\
\hline & ahpC 190 & $\mathrm{GCC} \rightarrow \mathrm{TCC}$ & $A \rightarrow S$ & & & & \\
\hline \multirow[t]{3}{*}{ oxyR-ahpC } & -46 & Insert one nucleotides $\mathrm{T}$ & & $1(1.6)$ & 1 & & 0.5 \\
\hline & -52 & $C \rightarrow A$ & & $1(1.6)$ & 1 & & $>2$ \\
\hline & -54 & $\mathrm{C} \rightarrow \mathrm{T}$ & & $2(3.1)$ & 2 & & $\geqslant 2$ \\
\hline$a h p C$ & none & None & & $0(0.0)$ & 0 & & \\
\hline \multirow[t]{2}{*}{$\operatorname{mabA-inhA}$} & -15 & $\mathrm{C} \rightarrow \mathrm{T}$ & & $5(7.8)$ & 2 & & $<0.25-1$ \\
\hline & & & & & 3 & & $\geqslant 2$ \\
\hline None & None & Wild type & & $10(15.6)$ & 8 & 2 & $\geqslant 2-4$ \\
\hline
\end{tabular}

Abbreviation: INH, isoniazid.

aMutations in the katG, inhA and $a h p C$ genes are denoted as follows: first, the amino-acid residue in the wild-type sequence; second, the codon position and third, the amino-acid residue in the mutated sequence.

bMutations in the oxyR-ahpC intergenic region and mabA-inhA regulatory region are denoted as follows: the nucleotide change is indicated relative to the start of the following open reading frame for mutations at the mabA-inhA regulatory region.

${ }^{\mathrm{C}}$ Bacterial strain is died.

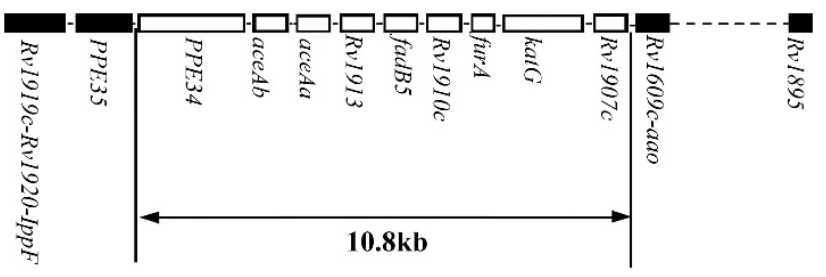

Figure 1 A 10.8-kb gene deletion fragment in WH56 isolates. White box represents for the genes deleted.

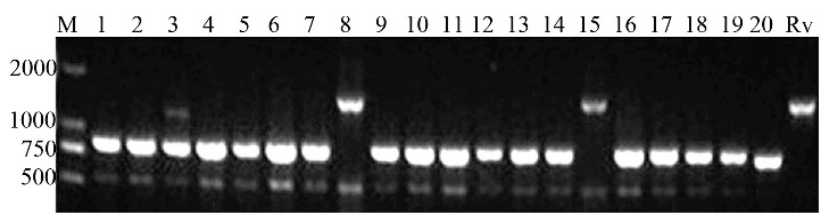

Figure 2 RD105 amplified by PCR. Lane M: DL 2000 Marker; Lane 1-20: 20 clinical stains; Rv: H37Rv (non-Beijing family strain).

than the $76.1 \%$ reported from isolates in Afghanistan. ${ }^{24}$ Nucleotide changes in codon 531: TCG $\rightarrow$ TTG, $51.7 \%$ (31/60), were more predominantly observed among isolates, and correlating to a higher frequency level of resistance to RIF MIC $\geqslant 8 \mu \mathrm{g} \mathrm{ml}^{-1}$ in our study
(Table 4). It is unclear whether novel mutation types E458A (GAG $\rightarrow$ GCG, MIC $\left.>8 \mu \mathrm{g} \mathrm{ml}^{-1}\right)$, P535S $\left(\mathrm{CCC} \rightarrow\right.$ TCC, MIC $>8 \mu \mathrm{g} \mathrm{ml}^{-1}$ ) and S509R (AGC $\rightarrow$ AGA, MIC $\geqslant 4 \mu \mathrm{g} \mathrm{ml}^{-1}$ ) are associated with RIF resistance because these isolates also carried mutations commonly associated with RIF resistance. ${ }^{25}$ Five isolates (8.3\%, MIC> $2-8 \mu \mathrm{g} \mathrm{ml}^{-1}$ ) had no mutation in the $r p o B$ gene, in accordance with the previous reports, ${ }^{20}$ which suggest that the mutations may be elsewhere or that there are unknown mechanisms of drug resistance.

It has been reported that $M$. tuberculosis resistance to INH was the first step in the evolution of a MDR phenotype. ${ }^{26} 71.7 \%(43 / 60)$ MDR isolates in our study were observed to have mutations in the $k a t G$ fragments, consistent with the reports from many different geographical regions. ${ }^{10,23,27}$ The most common mutation in the kat $G$ gene was at codon $315,62.5 \%\left(40 / 64, \mathrm{MIC} \geqslant 4 \mu \mathrm{g} \mathrm{ml}^{-1}\right)$, similar to the mutation rates previously reported as $72.7 \%$ in Shanghai, China, ${ }^{23}$ $68.4 \%$ in Cairo, Egypt, ${ }^{16}$ and $68.7 \%$ in California, USA. ${ }^{10}$ However, this is lower than the mutation rates reported in the Russian Federation (93.6\%) and in Brazil (87.1\%). ${ }^{23}$ It appears that mutation in katG 315 can show geographical differences in frequency and may not be a suitable independent marker for INH resistance. In this study, nucleotide changes in codon 315: AGC $\rightarrow$ ACC, $62.5 \%(40 / 64)$, were more predominantly observed among isolates, and correlating to a higher frequency level of resistance to INH $\mathrm{MIC} \geqslant 4 \mu \mathrm{g} \mathrm{ml}^{-1}$ (Table 5). However, it remains to be 
determined if the novel mutations G273S (MIC $>4 \mu \mathrm{g} \mathrm{ml}^{-1}$ ), I266T $\left(\mathrm{MIC}=4 \mu \mathrm{g} \mathrm{ml}^{-1}\right), \mathrm{P} 232 \mathrm{~S}\left(\mathrm{MIC}=4 \mu \mathrm{g} \mathrm{ml}^{-1}\right)$ and the $10.8-\mathrm{kb}$ deletion affect susceptibility to INH.

We also sequenced the structure genes of inhA and $a h p C$, the $m a b A$-inhA regulatory region and $\operatorname{oxy} R$ - $a h p C$ intergenic region. No mutation was detected in the structure gene of inhA in all 85 isolates. However, $12.5 \%(8 / 64)$ of the INH-resistant isolates harbored base substitutions $\mathrm{C}-15 \mathrm{~T}$ in the mabA-inhA regulatory region, consistent with the prior investigation..$^{28,29}$

In this study, only one mutation, A190S, in the inhA structural gene was found, coupled with S315T mutation in the kat G gene, a mutation frequency much lower than previous reports. ${ }^{30}$ Among all mutations in $\operatorname{oxy} R$-ahpC intergenic region, one isolate also had a G273S (GGT $\rightarrow$ AGT) novel mutation in kat $G$ gene. An association between $\operatorname{oxy} R$-ahpC intergenic region mutations and mutations in kat $G$ other than at codon 315 has been reported previously. ${ }^{31}$ Our results implied that the relationship between mutations of ahpC structural gene and $\operatorname{oxy} \mathrm{R}-a h p C$ intergenic region, and INH resistance still is not very clear, and is worthy of further investigation.

Of particular importance, in this study, were seven XDR isolates, accounting for $11.7 \%$ (7/60) of the identified MDR isolates, which is much higher than previous reports. ${ }^{32,33}$ Mutations in the XDR isolates were focused on $r p o B 531$ or $r p o B$ 526, and katG 315. Recently, however, Müller et al. reported that the percentage of isolates exhibiting mabA-inhA regulatory region $\mathrm{C}-15 \mathrm{~T}$ mutations increased significantly from $48.4 \%$ and $62.4 \%$, respectively, in MDR isolates to $85.5 \%$ and $91.9 \%$ in XDR isolates. ${ }^{34}$ The results of this study showed that only $42.9 \%(3 / 7)$ of XDR isolates were detected to have C-15T mutations, and these isolates also had an accompanying mutation in $\mathrm{kat} G$ gene. Hence, more studies need to be performed to investigate if the mabAinhA regulatory region was associated with the XDR isolates.

At the genetic level, gene alterations can change the structure of a target protein via mutations in the coding region or the amount of the protein expressed by modulating gene regulation, both of which ultimately cause the anti-drug resistance in M. tuberculosis.

In this study, the Beijing genotypes $(91.8 \%)$ were the major epidemic genotypes among the 85 clinical isolates. There are no visible differences between the Beijing genotype and drug resistance. Beijing genotypes account for $91.8 \%$ of all isolates and non-Beijing genotype account for $7.2 \%$. As the isolates in different regions had different characteristics, it is necessary to carry out studies on the relationship between Beijing genotype and drug resistance, pathogenicity and the ability to transmit.

In conclusion, this is the first report on the simultaneous genotypic analysis of the $r p o B, k a t G$, inh $A, a h p C$, mabA-inhA regulatory region and $\operatorname{oxy} R$-ahpC intergenic region in South-central China M. tuberculosis isolates. These six gene regions account for 95.0\% (57/60) of the MDR M. tuberculosis isolates. These information illustrate the need for further investigations to develop a more rapid and specific assay for the detection of MDR M. tuberculosis to be used as a screening method in areas. These observations also suggested that the drug resistance mechanisms of these first-line antituberculosis drugs were not completely clear and still need further research.

\section{CONFLICT OF INTEREST}

The authors declare no conflict of interest.

\section{ACKNOWLEDGEMENTS}

We are very grateful to Dr Stuart Wilson for his valuable comments on the manuscript, and also thank Xiaolong Liu, Zengling Sun and Shanshan Zhang for collecting M. tuberculosis isolates.
This work was supported by grants 2012ZX10003002-002 and 2013ZX10003002-005 from China Mega-Projects of Science Research for the 12th Five Year Plan, Grant D20121809 from Educational Commission of Hubei, China, Grant 12441903300 from the Science and Technology Commission of Shanghai Municipality, and grant 2010CX016 from Graduate Innovation Foundation of Wuhan Polytechnic University.

1 WHO. Multidrug and Extensively Drug-Resistant tb (m/xdr-tb): 2010 Global Report on Surveillance and Response (World Health Organization, Geneva, WHO/HTM/TB, (2010)).

2 Zhao, Y. et al. National survey of drug-resistant tuberculosis in China. N. Engl. J. Med. 366, 2161-2170 (2012)

3 Drobniewski, F. A. \& Wilson, S. M. The rapid diagnosis of isoniazid and rifampicin resistance in Mycobacterium tuberculosis-a molecular story. J. Med. Microbiol. 47, 189-196 (1998)

4 Wade, M. M. \& Zhang, Y. Mechanisms of drug resistance in Mycobacterium tuberculosis. Front Biosci. 9, 975-994 (2004).

5 Doustdar, F., Khosravi, A. D., Farnia, P., Masjedi, M. R. \& Velayati, A. A. Molecular analysis of isoniazid resistance in different genotypes of Mycobacterium tuberculosis isolates from Iran. Microb Drug Resist. 14, 273-279 (2008).

6 Dalla Costa, E. R. et al. Correlations of mutations in katG, oxyR-ahpC and inhA genes and in vitro susceptibility in Mycobacterium tuberculosis clinical strains segregated by spoligotype families from tuberculosis prevalent countries in South America. BMC Microbiol. 9, 39 (2009).

7 Dye, C., Williams, B. G., Espinal, M. A. \& Raviglione, M. C. Erasing the world's slow stain: strategies to beat multidrug-resistant tuberculosis. Science 295, 2042-2046 (2002)

8 Zhang, S. L. et al. Genotypic analysis of multidrug-resistant Mycobacterium tuberculosis isolates recovered from central China. Biochem. Genet. 45, 281-290 (2007)

9 Sajduda, A. et al. Molecular characterization of rifampin- and isoniazid-resistant Mycobacterium tuberculosis strains isolated in Poland. J. Clin. Microbiol. 42 2425-2431 (2004).

10 Metcalfe, J. Z. et al. Determinants of multidrug-resistant tuberculosis clusters, California, USA, 2004-2007. Emerg. Infect. Dis. 16, 1403-1409 (2010).

11 Tian, L. L. et al. Molecular epidemiology of Mycobacterium tuberculosis in Gansu province of China. Chin. Med. J. 19, 3458-3464 (2012).

12 Laura, F. et al. Large sequence polymorphisms classify Mycobacterium tuberculosis strains with ancestral spoligotyping patterns. J. Clin. Microbiol. 10, 3393-3395 (2007).

13 NCCLS National committee for clinical laboratory standards (NCCLS, Wayne PA, 2003).

14 Singh, U., Akhtar, S. \& Mishra, A. et al. A novel screening method based on menadione mediated rapid reduction of tetrazolium salt for testing of anti-mycobacterial agents[J]. J. Microbiol. Methods 84, 202-207 (2011).

15 Peng, Y. L. et al. Detection of the rpsL mutation for streptomycin-resistant Mycobac terium tuberculosis. Chin. J. Lab. Med. 23, 148-149 (2000).

16 Zhang, Z. Y. et al. Identification and pathogenicity analysis of a novel non-tuberculous mycobacterium clinical isolate with nine-antibiotic resistance. Clin. Microbiol. Infect. 19, 91-96 (2013).

17 Cole, S. T. et al. Deciphering the biology of Mycobacterium tuberculosis from the complete genome sequence. Nature 393, 537-544 (1998)

18 Tsolaki, A. G. et al. Functional and evolutionary genomics of Mycobacterium tuberculosis: insights from genomic deletions in 100 strains. Proc. Natl Acad. Sci. USA 101, 4865-4870 (2004).

19 Abbadi, S. H., Sameaa, G. A., Morlock, G. \& Cooksey, R. C. Molecular identification of mutations associated with anti-tuberculosis drug resistance among strains of $\mathrm{MyCO}$ bacterium tuberculosis. Int. J. Infect. Dis. 13, 673-678 (2009).

20 Hillemann, D., Weizenegger, M., Kubica, T., Richter, E. \& Niemann, S. Use of the genotype MTBDR assay for rapid detection of rifampin and isoniazid resistance in Mycobacterium tuberculosis complex isolates. J. Clin. Microbiol. 43, 3699-3703 (2005)

21 Jiao, W. W. et al. Molecular characteristics of rifampin and isoniazid resistant Mycobacterium tuberculosis strains from Beijing, China. Chin. Med. J. (Engl) 120, 814-819 (2007)

22 Homolka, S., Meyer, C. G. \& Hillemann, D. et al. Unequal distribution of resistance-conferring mutations among Mycobacterium tuberculosis and Mycobacterium africanum strains from Ghana. Int. J. Med. Microbiol. 300, 489-495 (2010)

23 Luo, T. et al. Selection of mutations to detect multidrug-resistant Mycobacterium tuberculosis strains in Shanghai, China. Antimicrob. Agents Chemother. 54, 1075-1081 (2010).

24 Bahrmand, A. R. et al. High-level rifampin resistance correlates with multiple mutations in the rpoB gene of pulmonary tuberculosis isolates from the Afghanistan border of Iran. J. Clin. Microbiol. 47, 2744-2750 (2009).

25 Sekiguchi, J. et al. Detection of multidrug resistance in Mycobacterium tuberculosis. J. Clin. Microbiol. 45, 179-192 (2007).

26 Dye, C. \& Espinal, M. A. Will tuberculosis become resistant to all antibiotics? Proc Biol. Sci. 268, 45-52 (2001). 
27 Zhou, A. et al. Molecular characterization of isoniazid-resistant Mycobacterium tuberculosis isolates from Xi'an, China. Microb. Drug. Resist. 17, 275-281 (2011).

28 Telenti, A. et al. Genotypic assessment of isoniazid and rifampin resistance in Mycobacterium tuberculosis: a blind study at reference laboratory level. J. Clin. Microbiol. 35, 719-723 (1997).

29 Van Rie, A. et al. Analysis for a limited number of gene codons can predict drug resistance of Mycobacterium tuberculosis in a high-incidence community. J. Clin Microbiol. 39, 636-641 (2001).

30 Saribas, Z. et al. Use of fluorescence resonance energy transfer for rapid detection of isoniazid resistance in Mycobacterium tuberculosis clinical isolates. Int. J. Tuberc. Lung Dis. 9, 181-187 (2005).
31 Hazbon, M. H. et al. Population genetics study of isoniazid resistance mutations and evolution of multidrug-resistant Mycobacterium tuberculosis. Antimicrob. Agents Chemother. 50, 2640-2649 (2006).

32 Sun, Z. et al. Characterization of extensively drug-resistant Mycobacterium tuberculosis clinical isolates in China. J. Clin. Microbiol. 46, 4075-4077 (2008).

33 Khanna, A. et al. Emergence and molecular characterization of extensively drugresistant Mycobacterium tuberculosis clinical isolates from the Delhi Region in India. Antimicrob. Agents Chemother. 54, 4789-4793 (2010).

34 Muller, B. et al. inhA promoter mutations: a gateway to extensively drug-resistant tuberculosis in South Africa? Int. J. Tuberc. Lung Dis. 15, 344-351 (2011). 